\title{
EXPANSÃO DA EDUCAÇÃO SUPERIOR NO BRASIL E A HEGEMONIA PRIVADO-MERCANTIL: O CASO DA UNESA
}

\author{
Deise Mancebo* \\ ANDRÉa ARAUjO DO VALE*
}

RESUMO: O trabalho apresenta a expansão da educação superior privada, a partir da análise de um caso exemplar: o da Universidade Estácio de Sá (Unesa). Para tal, foram analisados dados e documentos do Conselho Federal de Educação, das associações que representam o empresariado da educação, da Unesa, além da legislação pertinente. O texto sistematiza, inicialmente, os rumos privatistas da educação superior no país, acompanhando seus movimentos da ditadura militar à denominada "era das consolidações". A Unesa é tomada como fio condutor da argumentação, permitindo discussão aprofundada dos desenvolvimentos contemporâneos do setor, que compreendem: a concentração institucional, a financeirização e a internacionalização da educação superior (Faperj, Capes, Uerj).

Palavras-chave: Expansão da educação superior. Educação superior privada. Unesa.

\section{EXPANSION OF HIGHER EDUCATION IN BRAZIL AND THE PRIVATE-MARKET HEGEMONY: THE UNESA CASE}

ABSTRACT: The paper presents the expansion of private higher education, based on the analysis of an exemplary case: the Universidade Estácio de Sá (Unesa). In order to do so we have analyzed documents of Federal Council of Education, news from associations representing the business of education, Unesa's documents, and the relevant legislation. The text systematizes initially the directions of private higher education in Brazil, following its movements since the military dictatorship to the present moment. Unesa is taken as a thread for the arguments, allowing discussing the contemporary developments in the private higher education, which include: the institutional concentration, financialization and globalization of higher education (Faperj, Capes, Uerj).

Key words: Expansion of higher education. Private higher education. Unesa.

\footnotetext{
* Doutora em Educação e professora titular do Programa de Políticas Públicas e Formação Humana da Universidade do Estado do Rio de Janeiro (Uerj). E-mail: deise.mancebo@gmail.com

* Pós-doutoranda no Programa de Pós-Graduação em Políticas Públicas e Formação Humana da Universidade do Estado do Rio de Janeiro (Uerj). E-mail: andreaavale@ig.com.br
} 


\title{
EXPANSION DE L'ENSEIGNEMENT SUPÉRIEUR AU BRÉSIL ET L'HÉGÉMONIE DU MARCHÉ PRIVÉ: LE CAS DE UNESA
}

\begin{abstract}
RÉSUMÉ: Cet article présente l'expansion de l'éducation supérieure privée, à partir de l'analyse d'un cas exemplaire: l'Université Estacio de Sa (Unesa). À cette fin, ont été analysées les données et documents du Conseil Fédéral de L'éducation, des associations qui représentent le secteur privé de l'éducation, de l'Unesa, en plus de la législation pertinente. Le texte démontre initialement les trajectoires de la privatisation de l'enseignement supérieur dans le Pays, depuis les mouvements de la dictature militaire jusqu'à ce que l'on appelle «l'ère des consolidations». L'Unesa est considérée comme fil conducteur de l'argumentation, qui permet une discussion approfondie des développements contemporains du secteur, qui comprennent: la concentration institutionnelle, la financiarisation et la mondialisation de l'éducation supérieure (Faperj, Capes, Uerj).
\end{abstract}

Mots-clés: Expansion de l'éducation supérieure. L'enseignement supérieur privé. Unesa.

\section{Introdução}

$\mathrm{E}$ ste artigo apresenta uma reflexão sobre a expansão da educação superior privada no Brasil, a partir da análise de um caso exemplar: o da Universidade Estácio de Sá (Unesa). Parte do princípio de que a expansão da educação superior no Brasil é uma arena em que se desenrola uma longa luta entre o particularismo, o privatismo - característicos do capitalismo dependente e do padrão de escola superior daí resultante - e o público representado por forças democratizantes, estrutural e dinamicamente articulados na e pela formação social brasileira.

A expansão da educação superior brasileira é um tema complexo que abrange, pelo menos, quatro grandes linhas dignas de análise. Ela compreende: (1) ações do governo federal expandindo vagas, matrículas e cursos nas instituições federais de ensino superior (Ifes), seja pela multiplicação dos campi das Ifes já existentes, pela expansão do número de instituições, ou ainda mediante programas de reestruturação do setor, como é o caso do Programa de Apoio a Planos de Reestruturação e Expansão das Universidades Federais (Reuni), criado pelo Decreto Presidencial n. 6.096, de 24 de abril de 2007; (2) a expansão da pós-graduação com redefinição de seus rumos no sentido do empresariamento do conhecimento; (3) uma forte diferenciação de cursos, instituições e modalidades de ensino, cabendo destaque, desde o início desta década, à utilização do ensino a distância $(\mathrm{EaD})$ e (4) um expressivo aumento das instituições de ensino superior (IES) com fins lucrativos, isto é, privado-mercantis. Este texto sistematiza tão somente o último item: os rumos privatistas da educação superior no país. Acompanha seus movimentos, desde a ditadura militar, momento decisivo de expansão do setor e de fortalecimento do empresariado deste 
ramo; discute os anos de 1990, quando se desenha um novo momento da expansão do setor privado-mercantil, atrelado à crise do capitalismo mundial, ao modelo de educação terciária proclamado pelos organismos internacionais, à hegemonia neoliberal, que conduz à reforma do Estado brasileiro e a certa organização legislativa que favorece a privatização e termina destacando o movimento contemporâneo, a denominada "era das consolidações", cujos traços centrais são a concentração institucional - com as incorporações de pequenas instituições por grandes organizações -, a financeirização e a internacionalização da educação superior. Como dito, o fio condutor da análise do processo de expansão privatista é a apresentação e discussão da trajetória da Unesa, que se expressa como uma das maiores instituições de ensino superior no país em número de matrículas e cursos. Para a construção do texto, foram analisados dados e documentos do Conselho Federal de Educação (CFE), das associações que representam o empresariado da educação, da Unesa, inclusive suas demonstrações financeiras, além da legislação pertinente.

\section{Da Faculdade de Direito Estácio de Sá à Universidade Estácio de Sá: expansão do setor privado-mercantil, ditadura empresarial-militar e políticas educacionais}

Um dos atores centrais do processo de industrialização brasileira foi o Estado, tanto pela criação de empresas estatais e/ou de autarquias mistas, como pelo controle nacional sobre setores estratégicos da economia, pela criação de uma infraestrutura que possibilitou o desenvolvimento industrial privado, mas, sobretudo, pela viabilização de mecanismos que reordenam o desenvolvimento capitalista, permitindo a transferência de recursos para o setor privado empresarial. Em sua obra já clássica, A crítica à razão dualista, Oliveira (2006) mostra como o Estado atuou no desmantelamento do antigo modo de acumulação, com base na predominância da produção agrária para a exportação, e fundou e refundou as condições de novo modo de acumulação, calcado na atividade industrial. Uma das ações do Estado consistia na regulação do preço da força de trabalho - de preferência, próximo ao nível da subsistência -, atuando, por exemplo, na regulamentação das relações e condições de trabalho pelas "leis trabalhistas". A atenção às demandas do grande capital, estrangeiro ou associado, todavia, expressar-se-á, com o regime empresarial-militar, por novos caminhos, em especial em termos de padrão de atuação e de financiamento.

No plano político, pode-se observar como a transição da democracia populista para a ditadura civil-militar se inscreve como contenção da possibilidade de o Brasil assumir uma condição política independente e de liderança na América Latina e na África, bem como das ameaças ao poder burguês, representadas pela política de massas e pelo nacionalismo. 
Coube ao governo militar sanear a economia, especialmente em relação às altas taxas de inflação. O caminho encontrado para tal, segundo Fontes e Mendonça (1994), foi o de uma espécie de contencionismo, uma recessão calculada, que marcaria o período do regime civil-militar entre 1964-1967 e que prepararia a expansão do denominado "milagre econômico".

No plano político, a ditadura civil-militar moveu-se, sinteticamente, na disposição de assegurar as condições necessárias para a definitiva inserção dependente e associada do Brasil no sistema econômico mundial (FERNANDES, 1973, 2006), o que significou, em termos de atuação do Estado, levar ao ponto extremo a centralização do poder político, bem como eliminar, pela repressão mais exacerbada, as formas de participação e contestação política.

A política educacional foi motivo particular de intervenção, diante da necessidade de conter o movimento social em torno da reforma universitária crítica. Além da coerção exercida contra os docentes, o movimento estudantil foi alvo especial de acirrada repressão e desmantelamento e, em 1968, como culminância, uma reforma universitária dentro da ordem (Lei n. 5.540/68) foi implementada. Neste dispositivo legal, a ditadura tentou articular a educação nacional ao tipo de desenvolvimento econômico que buscava promover, colocando a educação superior, por um lado, como espaço estratégico para a produção de ciência e tecnologia e, por outro, também para a formação de recursos humanos. É nesta trilha que o regime militar buscou soluções para a expansão das universidades públicas e para sua "modernização" nos novos padrões de dependência.

As medidas tomadas, legais ou não, foram, no conjunto, muito eficientes no que tange ao desmantelamento do movimento estudantil e ao controle das atividades docentes, o que incluiu uma opção clara pela expansão do sistema de educação superior pela via privada, substancialmente através de instituições (IES) de tipo privado-mercantil, acompanhada pelo estrangulamento das IES públicas, que significou:

\footnotetext{
A emergência de um "novo ensino superior privado", de perfil laico, comandado por uma lógica de mercado e por um acentuado ethos empresarial que foi se constituindo a partir do final dos anos de 1960. Esse segmento laico passou a pressionar pela abertura de novas instituições, guiado pela percepção da existência de uma demanda reprimida, na qual se destacavam "os excedentes" e também uma crescente clientela potencial, resultante da ampliação da rede de segundo grau. (MARTINS; VELLOSO, 2002, p. 811-812; grifos nossos)
}

Assim, impulsionados por uma política educacional "generosa" - claramente identificada no plano do pensamento educacional e nas práticas do Conselho Federal de Educação $(\mathrm{CFE})^{1}$-, os empresários da educação puderam abrir novos estabelecimentos de ensino, em sua maioria, faculdades isoladas de pequeno porte, mais 
baratas, mais rápidas e fáceis de pôr em funcionamento do que as universidades, com cursos na área das ciências humanas e sociais, que contavam com maior demanda, além de serem mais baratos. De acordo com Martins e Velloso (2002), dos 938 pedidos de abertura de novos cursos recebidos pelo CFE entre 1968 e 1972, foram autorizados 759 pedidos (mais de $80 \%$ ) e, com este tipo de expediente, o setor privado expandiu-se, atendendo a desafios postos ao regime autoritário: suprir a demanda excedente para o ensino superior, abrindo para a classe média um caminho visto como de ascensão social e, no mesmo golpe, ajudar a minar a movimentação político-estudantil.

Neste ponto, é fundamental que se defina que a expansão pela via privada não significou a absoluta ausência de financiamento estatal, pois muitas dessas instituições privado-mercantis gozaram de uma série de isenções fiscais e previdenciárias que as beneficiaram, do ponto de vista patrimonial e de ampliação de sua liquidez, como é o caso da instituição aqui analisada. Assim, é preciso cuidar para que não se entenda a expansão com contenção como crescimento sem nenhum financiamento, direto ou indireto, do Estado. Carvalho (2002) enumera uma série de subsídios e possibilita uma compreensão mais precisa do novo modelo de financiamento das IES privadas a partir da Reforma Universitária. Segundo a autora:

Pode-se concluir que os mecanismos de financiamento direcionados às instituições privadas, criados a partir da Reforma Universitária, foram mais sofisticados e complexos que aqueles sugeridos pelos atores envolvidos no processo. Isto decorre da reformulação no financiamento governamental à atividade privada no Brasil, já desenhado no período de 1964 a 1967. O financiamento direto e amplo foi substituído em todos os setores econômicos por estímulo indireto. O sistema educacional não fugiu à regra, os recursos via verbas orçamentárias transformaram-se em política tributária traduzida em incentivos fiscais vinculados a projetos e programas. Estes mecanismos permitiram a sustentação do crescimento das instituições privadas em curso em meados dos anos de 1960. (CARVALHO, 2002, p. 91; grifos nossos)

É evidente a relação entre as isenções fiscais e o processo de expansão do setor privado no sistema de ensino superior. Segundo a autora, a imunidade de Imposto Predial sobre Propriedade Urbana (IPTU) permitiu a aquisição de um número maior de imóveis, para alojar mais alunos e cursos, o que favoreceu o crescimento do número de campi, servindo até para o aumento do ativo imobilizado. A imunidade de Imposto Sobre Serviço de Qualquer Natureza (ISS) veio favorecer a expansão das matrículas e, com isso, o crescimento da Receita Operacional Bruta (ROB), uma vez que liberou a tributação sobre a prestação de serviços. A imunidade do Imposto de Renda (IR) permitiu não apenas a reprodução das atividades, mas foi bastante eficaz na sustentação da saúde financeira das IES. Por sua vez, esta tornava viável o financiamento bancário, o auxílio externo e o recurso a agências de fomento. Para as entidades filantrópicas, a isenção da cota patronal do Instituto Nacional de 
Seguridade Social (INSS), antigo Instituto Nacional de Previdência Social (INPS), facultou a expansão do corpo docente e do pessoal técnico-administrativo porque o aumento da folha de pagamento não engendrava aumento de custos operacionais. Entre 1974 e 1980, também funcionou o Programa de Auxílio às Instituições não Federais (Panf), que destinava recursos a qualquer IES para despesas com construção, equipamentos etc. e que teve um papel mais relevante para as IES de pequeno porte (CARVALHO, 2002). Por fim, o Programa de Crédito Educativo (Creduc), criado em 1975, foi outro incentivo importante para a manutenção do setor privado: consistia em um empréstimo para o pagamento de mensalidades ou para a manutenção de estudantes carentes matriculados, respectivamente em IES privadas ou públicas. Pode-se afirmar que, a rigor, o programa foi instituído quando a ordenação econômica do "milagre econômico" começou a falhar, revelando a necessidade de injeção de recursos públicos para a manutenção dos alunos nas IES privadas. Em síntese, foi uma iniciativa voltada para a manutenção da demanda nas IES privadas no período posterior a 1975. Na década de 1980, o Creduc foi reformulado (fim das bolsas de manutenção, nova fonte de recursos, contratos por anuidades e alteração nas condições de empréstimo) e, segundo Davies (2002), chegou aos anos de 1990 com um grau de inadimplência alto, correção subestimada dos empréstimos, sendo seu saldo devedor estimado em $\mathrm{R} \$ 450$ milhões, sendo substituído pelo Fundo de Financiamento do Ensino Superior (Fies), em 1999.

É no bojo deste processo de ativa participação do Estado na privatização da educação superior brasileira, que a Sociedade de Ensino Superior Estácio de Sá (Seses) - constituída em 5 de março de 1969 e que se apresentava como sociedade civil sem fins lucrativos - encaminhou, em 1970, à Câmara de Ensino Superior (CESu) do CFE um pedido de autorização (Processo n. 637/70) para o funcionamento da Faculdade de Direito Estácio de Sá (Fades), na Rua do Bispo, no Rio de Janeiro, tendo como fundador o então magistrado João Uchôa Cavalcanti Netto, figura que publicamente marcou a trajetória da instituição.

O voto do relator, acompanhado pelo próprio parecer da Câmera de Educação Superior, foi no sentido de que o processo deveria baixar novamente em diligência para resolver a pendência relativa à biblioteca e apresentação de um quadro geral de horário de trabalho de cada professor para que se pudesse avaliar a compatibilidade. As exigências foram rapidamente solucionadas, uma vez que dois dias depois a autorização para o funcionamento da faculdade foi concedida, pelo Parecer CFE n. 422/70, e o curso teve início com oitenta alunos em cada turno (manhã e noite), totalizando 160 discentes.

A instituição cresceu rapidamente, abrindo novas faculdades e cursos, como a Faculdade de Ciências Econômicas e Administrativas (1971), a Faculdade de Comunicação Social (1972), passando, em 1972, ao regime de Faculdades Integradas 
(Fies) e efetivando, em 1973, a mudança para um Regimento Unificado, atualizado à medida que a instituição ia crescendo e novos cursos iam sendo criados. Ainda em agosto de 1972, foi inaugurado o campus Rebouças, ${ }^{2}$ segundo dados da própria instituição. Em 1975, a mantenedora da Seses foi reconhecida como de utilidade pública estadual (Lei n. 1.536, de 3 de janeiro de 1975) e, em 1981, como de utilidade pública federal (Decreto n. 86.072, de 4 de junho de 1981), caracterização fundamental para se candidatar a qualquer forma de isenção fiscal, da qual só abriria mão em 9 de fevereiro de 2007. Em 1978, segundo a Estácio Participações S.A. (2011), a instituição inaugurou sua pós-graduação.

Deve-se acrescentar que a Sociedade de Ensino Superior Estácio de Sá registrou seu Estatuto Social em 30 de maio de 1979, no Registro Civil de Pessoas Jurídicas, definindo-se, na ocasião, como uma sociedade civil de caráter filantrópico sem fins lucrativos, já tendo recebido, em janeiro de 1974, o certificado de fins filantrópicos do então Conselho Nacional de Serviço Social, com a afirmação - requisito para a concessão do certificado - de que seus sócios ou Conselho de Curadores não recebiam qualquer remuneração derivada de suas atividades na instituição.

Apenas para se ter uma ideia do quanto as isenções podem ter significado financeiramente para a instituição, na primeira demonstração financeira realizada pela auditoria Ernest \& Young, quando da formação da Companhia Estácio Participações S.A., em 31 de março de 2007, informou-se que R $\$ 96$ milhões e 482 mil reais - de um valor patrimonial, em cotas da Seses e das outras mantenedoras, de R\$ 123 milhões e 554 mil - "[...] foi registrado na Companhia em rubrica específica de reserva de capital (ágio na subscrição de ações)" o que se referia, substancialmente, "ao saldo remanescente dos resultados acumulados auferidos pelas empresas controladas (Seses e Mantenedoras) antes da transformação de sua forma jurídica de entidades sem fins lucrativos para sociedades empresárias" (ESTÁCIO PARTICIPAÇÕES S.A., 2007a, p. 27).

Exatamente por essas razões, defende-se aqui a ideia de que as IES empresariais puderam crescer, para além do financiamento recebido das mensalidades, especialmente, a partir de isenções fiscais e tributárias bastante generosas e percebidas, apontando para a clara presença do fundo público na reprodução ampliada do setor.

Nos anos de 1980, à revelia das lutas pela redemocratização e pelos direitos sociais (entre eles o da educação pública), emerge um novo perfil de instituição superior privada, em grande parte na tentativa de adequação ao novo momento político do país. No caso da Estácio, é a partir desta década que começa uma preparação para sua transformação em universidade pela via do reconhecimento, um caminho mais rápido para auferir as vantagens que a autonomia universitária concede. Em 
1986, a Seses encaminhou ao CFE carta-consulta para sua transformação em universidade, o que atenderia, aparentemente, à Lei n. 5.540/68, que postulava ser a universidade a instituição modelar para o ensino superior. A autonomia era uma prerrogativa das instituições universitárias e, no que já se delineava, então, assim permaneceria na Constituição Federal de 1988.

A Comissão de Consultores foi constituída por meio da Portaria CFE n. 4, de 30 de janeiro de 1987, e era integrada pelos professores Lauro Ribas Zimmer, Ronald Braga e Edi Madalena Fracasso. Os trabalhos da Comissão foram inicialmente acompanhados pelo relator Tarcisio Guido Della Senta, que, em razão de seu afastamento do país, foi substituído pelo conselheiro Ernani Bayer. Segundo o Parecer n. 1.205/88 (CFE, 1988), foram efetuadas várias visitas pela Comissão e realizadas reuniões para a verificação das condições de passagem ao status de universidade. Para o relator, a Comissão teria realizado um excelente trabalho, não só de apreciação da proposta de transformação, mas também em termos do acompanhamento das providências a serem adotadas, tendo sido, portanto, fator de mudança na instituição. "O progresso institucional ocorrido no período de acompanhamento deve-se, em grande parte, ao estímulo e a [sic] orientação produzidos pelos integrantes da referida Comissão" (CFE, 1988, p. 2). Entre outros aspectos, nos singelos dois anos de duração do processo, a pleiteante conseguiu implementar - pois ainda não o teria feito - a cultura da pesquisa e da extensão, própria às universidades!

Sobre o pessoal docente, o Parecer indicava que, em junho de 1988 - cerca de cinco meses antes de sua votação -, a instituição havia iniciado um plano de carreira dos docentes, atendendo tanto aos acordos firmados com os sindicatos, quanto às demandas dos próprios docentes. Todavia, a declaração de Cavalcanti Netto, concedida anos depois (em 2002), é muito mais evidente quanto ao que se pensava sobre os docentes e sua formação na nova universidade:

Eu acho totalmente irrelevante quantos doutores eu tenho, quantos mestres [...]. Isso não faz uma faculdade ser boa. O professor mestre, doutor e pós-doutor não é melhor do que um professor recém-formado, se ele for talentoso [...]. (CAVALCANTI NETTO, 2002, p. 345)

O Parecer n. 1.205/88 cita ainda a distribuição dos então 454 professores pelos seguintes setores: Centro de Ciências Jurídicas - 63; Centro de Ciências Sociais - 146; Centro de Ciências Humanas - 136; Centro de Ciências Biológicas e da Saúde - 45; e Centro de Ciências Tecnológicas - 64, confirmando a centralidade dada pelas IES privadas às áreas de ciências humanas e sociais, que, no caso da Seses, concentrava $76 \%$ do corpo docente. Este apresentava, então, a seguinte formação: doutorado $-3,3 \%$; mestrado - $14,5 \%$; doutorando $-1,1 \%$; mestrando $-3,5 \%$; especializados $-38,1 \%$; e graduados $-39,5 \%$, ao que o CFE recomenda uma maior 
qualificação. É citado ainda o sistema de incentivo aos docentes, referindo-se aos adicionais por tempo de serviço, no percentual de 2,5\% a cada biênio, bem como aos adicionais por qualificação para doutor, mestre ou especialista, no percentual de 15,10 ou $5 \%$, respectivamente. ${ }^{3}$

Assim, a Comissão de Consultores, após análise dos variados aspectos já citados em mais de uma ocasião, apresenta as seguintes conclusões: a instituição mantenedora apresenta regularidade em termos fiscais e parafiscais, saúde patrimonial e financeira, apesar das oscilações nos anos anteriores. Comprova experiência e tradição na manutenção de IES, operando de forma harmoniosa e sem interferir na autonomia didático-pedagógica da entidade mantida, o que garante a autonomia universitária. A Comissão Especial para Análise de Processos de Criação e Reconhecimento de Universidade acompanhou o parecer da Comissão de Consultores, sendo a decisão da Câmara aprovada por unanimidade no Plenário do CFE, em 1988.

Quando perguntado sobre a razão de ter feito o pedido de transformação da Estácio numa universidade, Cavalcanti Netto (2002, p. 332-333) afirma:

\begin{abstract}
A única importância, para mim, de ser universidade, era a seguinte: sendo faculdade, quando queria abrir um curso novo, tinha que fazer um pedido ao $M E C$, e esse processo às vezes levava anos. Sendo universidade, abria o curso que quisesse à hora que quisesse, podendo atender com mais rapidez às necessidades sociais que emergiam numa época de muita transição. Para mim, a única importância em ser universidade era isso: eu queria poder abrir o curso que quisesse e dentro da lei. (Grifos nossos)
\end{abstract}

Um pouco mais adiante, na mesma entrevista, Cavalcanti Netto argumenta que, se já existisse na época a figura do Centro Universitário, bastaria, pois não era propriamente a chancela de universidade o que buscava, mas a autonomia para a criação dos cursos.

Neste ponto da história institucional, faz-se mister salientar uma reflexão sobre o modo de condução das políticas educacionais, de elaboração das normas legais e sobre a atuação do empresariado educacional forjado no bojo do regime empresarial-militar. Todos esses vetores, em conjunto, pareciam responder menos às necessidades educacionais ou a um planejamento da expansão do setor educacional do que às demandas mercantis do empresariado do setor. As políticas estatais, como no caso do financiamento por estímulo fiscal, por exemplo, bem como as normas reguladoras, como as definidas pelo $\mathrm{CFE}$, sem descartar a penetração nessa instância dos representantes do próprio empresariado, convergem para a busca de vantagens ao setor privado, contorno das exigências e cobranças à sua atuação e constituem certo padrão de educação superior bem denominado por Fernandes (1973) de dependente. 


\section{A trajetória da Sociedade de Ensino Superior Estácio de Sá: da dé- cada de 1990 à Educação S.A.}

Os anos de 1990 demarcam, no Brasil, um momento em que as conquistas mais significativas emergidas das lutas contra o regime ditatorial, mesmo que já atravessadas por movimentos conservadores e antidemocráticos, sofrem um imenso ataque, articulado na tentativa de compor um novo patamar de acumulação capitalista capaz de, supostamente, superar ou conter a crise de acumulação que explode nos anos de 1970, nos países centrais. Na década de1980, já se podia observar a presença de processos que preparam, sob a batuta dos organismos internacionais, a implantação das políticas neoliberais, das reformas de Estado e de partícipes mais ou menos servis, mais ou menos "interessados" na financeirização mundializada que se desenha desde então.

O regime de acumulação com predominância financeira, como afirma Chesnais (2005), não aparece sem engendrar um intenso e extenso processo de reestruturação produtiva, apoiada sob a base tecnológica construída a partir das novas tecnologias da comunicação e informação. Nesta perspectiva, a própria produção do conhecimento e da tecnologia é atravessada por novas demandas, que concretizam certa racionalidade, exigindo a reforma dos sistemas educacionais, especialmente no nível da educação superior. Essas mudanças não se dão apenas em uma direção, mas expressam movimentos do capital em sua existência contraditória. No Brasil, por exemplo, verifica-se, por um lado, um incremento da produção de conhecimento e de tecnologia, basicamente desenvolvidos na universidade pública, que possibilita, no limite, maiores ganhos de produtividade e de lucratividade, principalmente quando produzidos com o precioso auxílio do fundo público de modo mais ou menos direto. Mas também se expressa pela própria transformação da educação superior em um importante espaço de acumulação, o que se concretiza pelo incremento na atuação das IES privadas no mercado da certificação em massa, na reorganização da formação em nível superior, na adoção de determinados valores afinados com as formas de sociabilidade típicas do capitalismo tardio.

A Universidade Estácio de Sá, na década de 1980, inicia seu ciclo de expansão como universidade, status reconhecido em 1988. Por um lado, já detinha a almejada autonomia para a abertura de cursos e oferta de vagas, por outro, soube aproveitar "sabiamente" a demanda latente por ensino superior por parte das classes médias e populares. A Unesa expande-se em direção à Barra da Tijuca, zona oeste do Rio de Janeiro, ainda em 1992, e em 1996 abre diversos campi no interior do estado, em municípios como Resende, Nova Friburgo e Niterói. Em 1997, cria o denominado Instituto Politécnico, no qual concentrou os cursos sequenciais ou, conforme anunciado nos dias atuais, a graduação tecnológica. Sobre o Politécnico, é importante ressaltar 
que este é proposto, pela Estácio Participações S.A. (2007a), pelo fato de ser capaz de mobilizar o desenvolvimento de habilidades e competências que atendessem às demandas mais imediatas do mercado e que teria como público aqueles que já estão no mercado de trabalho e querem se qualificar e aprimorar seu potencial de empregabilidade. É evidente que a real importância atribuída ao Politécnico residia na durabilidade do curso e na sua capacidade de retorno, independentemente do aluno, como o trecho a seguir bem demonstra.

\begin{abstract}
Estamos sempre atentos às novas demandas do mercado e possuímos histórico de sucesso na identificação e abertura de novos cursos, visando capturar demanda reprimida. Possuímos sistemas de gestão e controle que nos permitem avaliar o desenvolvimento e retorno econômico de todos os cursos, de forma a verificar critérios mínimos de rentabilidade, e, caso necessário, decidir pelo encerramento dos cursos que não se mostrem lucrativos. (ESTÁCIO PARTICIPAÇÕES S.A., 2007a, p. 22)
\end{abstract}

Em 1998, é a vez de iniciar sua expansão nacional: São Paulo, Minas Gerais, Espírito Santo, Santa Catarina, Mato Grosso do Sul, Bahia, Pernambuco, Pará e Ceará foram alguns estados que receberam unidades da Unesa. Entretanto, a Seses não se expandiu privilegiando a Unesa em nenhum destes estados. Nas demonstrações financeiras apresentadas pelos auditores da Ernst \& Young, em 2007, percebe-se que em nenhum destes estados aparece a Estácio sob a forma de universidade, apresentando-se sob o formato de faculdade.

Atualmente a Seses possui 48 unidades em sete estados brasileiros e é composta por uma universidade - Universidade Estácio de Sá - e oito faculdades. A Universidade Estácio de Sá conta [ainda] com 39 unidades espalhadas no Rio de Janeiro. (ESTÁCIO PARTICIPAÇÕES S.A., 2007a, p. 15; grifos nossos)

Fora do Rio de Janeiro, têm-se instituições comandadas por outras mantenedoras que foram incorporadas pela Estácio Participações S.A., ${ }^{4}$ empresa fundada em 2007 e que é, na realidade, a holding que controla outras mantenedoras e estas às respectivas IES. Esse holding abriu capital na Bolsa de Valores em julho de 2007, incorporando-se ao mercado financeiro. Em seu Estatuto Social define sua sede (cidade do Rio de Janeiro), seu caráter de sociedade por ações e seus objetivos sociais que caminham em duas direções: a continuidade de suas atividades no eixo da educação superior e/ou de outras atividades educacionais e sua participação como acionista ou sócia de outras empresas, bem como a administração de seus próprios negócios. É possível, então, apontar alguns direcionamentos da Companhia: primeiro, a "possibilidade" de espraiar suas atividades para além do ramo da educação superior ou profissional, na direção de outras áreas associadas à educação, como, por exemplo, a produção de material didático. Além disso, passa a ocorrer a valorização de capital pela via financeira, com a participação societária ou acionista 
em outras empresas, incluindo a internacionalização, como sendo um de seus objetivos estatutariamente assumidos, tornando-se o ensino superior, portanto, um dos braços de um conglomerado, de uma corporação. Nas Informações Anuais (IAN) de 2007 (Estácio Participações, 2007b), a orientação para a expansão das atividades é anunciada como um ponto forte da empresa e que se deve realizar pelo aumento no número de alunos matriculados nas IES sob controle do holding, pela abertura e/ ou aquisição de novas unidades e pela inovação na oferta de cursos.

A empresa remete-se à lógica expansiva em si mesma, ou seja, como organização empresarial financeirizada é constituída por uma racionalidade que a leva a buscar constante expansão como forma de aplicar seus excedentes, ganhar em competitividade e, principalmente, ampliar e/ou manter suas taxas de lucratividade. Nessa lógica, crescer não é uma opção educacional, mas uma necessidade financeira. A Estácio demonstra ter uma clara percepção deste novo contexto do processo de mercadorização da educação superior, ou seja, dos novos mecanismos a serem utilizados para transformar a educação superior em um bem comercializável, um objeto de lucro ou acumulação (SGUISSARDI, 2008). O novo contexto é caracterizado, enfim, pela consolidação, pela formação de grandes conglomerados educacionais, dos quais alguns já são empresas financeirizadas. Como afirma Ryon Braga, representante da consultoria Hoper Educacional (apud TIRADENTES, 2009, p. 104), “O setor tem um brutal poder de economia de escala [...]. A consolidação é irreversível". A Estácio Participações S.A. apresenta-se como um player repleto de vantagens neste processo e ela própria oferece um diagnóstico preciso sobre a questão: "a elevada fragmentação [do sistema privado de educação superior] representa forte potencial de consolidação futuro do setor, o qual deve ser liderado pelas instituições que apresentam maior porte, recursos financeiros e capacidade instalada atualmente" (ESTÁCIO PARTICIPAÇÕES S.A., 2007a, p. 43; grifos nossos). A Estácio coloca-se explicitamente como uma dessas lideranças, a ponto de anunciar no seu site, como visão, a pretensão de "ser o maior grupo privado de educação superior do mundo em número de alunos até 2015, com equipes de alto desempenho, excelência na prestação de serviços e em rentabilidade" (ESTÁCIO PARTICIPAÇÕES S.A., 2010; grifo nosso). Veja-se que a racionalidade que conduz à expansão não é definida pelas necessidades sociais e/ou acadêmicas, mas por um planejamento financeiro calcado na busca da lucratividade.

Outro aspecto que merece atenção refere-se às estratégias de captação e retenção de alunos com base em ações de marketing e também pela via das parcerias. Pode-se observar como a propaganda produzida pela instituição busca ressaltar a sua conexão mais direta com o mercado de trabalho, seja pelas parcerias que promovem atividades de estágio, seja porque oferece uma formação mais adequada às novas demandas do mercado de trabalho. 
Em balanço patrimonial apresentado por auditoria quando do pedido de abertura de capital junto à Comissão de Valores Mobiliários (CVM), em 31 de março de 2007, são apresentados uma série de dados sobre a Companhia que mostram os mecanismos empresariais utilizados nas relações entre Estado e empresa. Mais uma vez fica evidente que a lucratividade das empresas educacionais depende do suporte e do financiamento estatal pela via das isenções, e mesmo a transformação em sociedade empresarial com fins lucrativos não significou para a Estácio Participações S.A. a dispensa dessa importante "ajuda" para a saúde financeira da Companhia. Segundo o Informe Financeiro Anual (IAN), publicado pela Estácio Participações S.A.:

\begin{abstract}
A isenção de tributos permitida pelo programa [Programa Universidade para Todos ou Prouni] permitiu a elevação dos investimentos, especialmente por instituições privadas, já que esta permite a manutenção de custos mais reduzidos e preços competitivos a fim de enfrentar a concorrência, bem como elevar a oferta de curso para indivíduos de renda baixa e média baixa. (ESTÁCIO PARTICIPAÇÕES, 2007b, p. 44; grifos nossos)
\end{abstract}

Assim, conforme avaliação do próprio setor, o Programa Universidade para Todos (Prouni) é um importante "financiamento público", mesmo que indireto, ao segmento privado. Em outros termos, a renúncia fiscal proveniente do Programa é reconhecida como um aquecimento à rentabilidade dos estabelecimentos educacionais privados (com ou sem fins lucrativos), em nome de uma suposta democratização do acesso à educação superior. ${ }^{5}$

É muito curioso que, quando a imprensa fala do Prouni e das isenções que este promove, raramente atenta para seu volume e seu significado concreto, que é o de socorro ao setor educacional empresarial. Ao contrário, como se verifica na citação anterior, os empresários têm plena consciência da importância deste Programa de isenção fiscal, fundamental em um momento em que o setor dá amostras de crises, produzidas pelo quase esgotamento da capacidade de pagamento de seu público.

A entrada no Prouni e outras "ajudas" estatais, acompanhadas de uma eficiente gestão, garantiram à Estácio Participações uma receita bruta, em 2007, de R\$ 1,3 bilhões e uma receita líquida de R\$ 860 milhões (ESTÁCIO PARTICIPAÇÕES S.A., 2007a, p. 70). Em maio de 2008, a Estácio Participações S.A. celebra a venda de $20 \%$ de seu capital social para a Moena Participações S.A., uma empresa aberta, diretamente controlada pela Garantia Participações (GP), ${ }^{6}$ braço de investimento do Banco Garantia, conhecido pela administração flexível, gerida por uma meritocracia rígida, inclusive em termos de remuneração de seus funcionários. O pagamento do preço de aquisição - $\mathrm{R} \$ 259.330 .720,00$ - foi feito em moeda corrente, à vista. Tal aquisição revela um compartilhamento da gestão da Estácio Participações S.A. entre os sócios fundadores, principais acionistas, e a GP, por tempo determinado, para incrementar o valor da Companhia. 
A Garantia Investimentos S.A. assumiu, em sua administração, princípios oriundos da cultura do mercado financeiro que têm deixado profundas marcas nas IES, como os Programas de Remuneração Variável, os Programas de Incentivo à Qualificação e Códigos de Ética e de Conduta. Outro aspecto a se destacar é seu modus operandi em termos administrativos, como, por exemplo, o Orçamento Base Zero, no qual se parte sempre do zero na elaboração do orçamento do ano seguinte, esmiuçando e enxugando toda despesa considerada como "gordura". Na verdade, a presença na gestão da Estácio Participações se faz por meio de um fundo de Investimento em Participações, o GPCPIV (2007), gerido pela GP, que também é aplicado em outros investimentos. A rigor, a Estácio Participações S.A teve 20\% de suas ações compradas por um dos fundos geridos pela GP Investments, formado por Private Equity C, LLC (coinvestidor) e GPCPIV. Como resultado de todo esse empenho, entre outros, em 2008, o grupo consolidou aquisições anunciadas anteriormente e incorporou doze novas empresas mantenedoras e suas respectivas IES. ${ }^{7}$

O ano de 2009 foi marcado, no plano mundial, pelas reverberações da crise de 2008, relacionadas, sobremaneira, com a hipertrofia financeira. Todavia, para a Estácio Participações S.A. o ano terminou bem. As demonstrações financeiras com data-base em dezembro de 2009 (ESTÁCIO PARTICIPAÇÕES, 2009) mostram um aumento de 1,8\% de margem Ebitda. Mesmo sofrendo uma baixa de 6,9\% no número de alunos, obteve um aumento de $2,9 \%$ de receita líquida. A receita bruta chegou ao total de R $\$ 1.459,7$ bilhões, tendo aumentado 1,9\% por causa de aumentos das mensalidades. Cabe destaque que, neste contexto, o uso do ensino a distância (EaD) apresentou-se fortemente como uma estratégia viável e necessária.

No ano de 2010, ocorre nova oferta pública de ações, advinda da venda das ações do fundador da Seses, João Uchôa (recém-falecido), e de sua filha, Monique. Ocorre, ainda, exponencial crescimento do segmento da EaD, que chegou a 26,2 mil alunos no final do ano (eram 7.500 no ano anterior), compensando a perda de alunos presenciais, de modo que a instituição fecha o ano de 2010 com 210 mil alunos. A receita bruta foi de $R \$ 1.016 .1$ milhões e a receita líquida de $R \$ 860$ milhões. A expansão se realizou com a aquisição de duas novas unidades e mais quatro a serem inauguradas em 2011.

Ao se observar a composição acionária da empresa ao fim de 2010, pode-se verificar a saída do fundador, a recomposição da participação da GP Investimentos e, aspecto mais que relevante: nessa nova composição desaparece a figura do acionista controlador. Assim, uma das maiores empresas educacionais do país tem seu controle pulverizado por uma série de investidores, que não se sabe quem são, onde estão e o que querem em termos de "projeto educacional", aprofunda-se a administração gerencial centrada em redução de custos-economia de escala, no aumento 
das margens de lucro para remuneração dos acionistas e alimentação da própria expansão, especialmente pela via financeira.

\section{Considerações finais}

Tivemos a intenção de apresentar, de modo bastante resumido, duas ordens de consideração neste texto. Em primeiro lugar, dados relativos ao crescimento e expansão da instituição Estácio de Sá. Pode-se perceber como essa empresa educacional apresentou franca expansão, contando com o fértil solo de financiamento estatal, mesmo que indireto. Sua potencialidade expansionista, no regime empresarial-militar, estava escorada pelo pensamento e pelas práticas privatistas do Conselho Federal de Educação que, nesse sentido, foi o grande delineador da expansão das IES privado-mercantis. Mas o setor privado também se escudou em formas de financiamento estatal indireto que foram fundamentais para o crescimento do setor, preparando o tipo de expansão que se faria nos anos de 1990.

O desenvolvimento de IES privadas na década de 1990 vai se realizar sem modificar esta estrutura, que permanece e se aprofunda. Nesta década, estabelece-se um novo ciclo de expansão da educação superior no país, marcado pela presença de empresas de prestação de serviços educacionais que, de fato, funcionam como grandes grupos empresariais e que se movimentam, mais do que por sua atividade-fim - a educação -, pela sua capacidade financeira de conquistar espaço no mercado. $\mathrm{Na}$ avaliação ora esboçada, essas grandes empresas representam oportunidade de investimentos para o capital financeiro mundializado. Ainda é relativamente pequena sua participação no setor, mas é possível que esse quadro se agrave, especialmente quando sucessivos governos implementam planos de educação e programas que se pautam por essa racionalidade - não apenas pelas "brechas", mas por um delineamento mesmo de programas e projetos - que beneficiam esse setor do capital que busca avidamente oportunidades de investimento e expansão. No mesmo processo, deixa-se a formação superior de milhares de brasileiros (em expansão para latinoamericanos) nas mãos de empresas educacionais que, como se apresentou, sequer se sabe quem são seus donos!

\section{Notas}

1. O golpe civil-militar, deflagrado em 31 de março de 1964, requereu ajustes na educação. Esses novos dispositivos legais - em especial a reforma universitária instituída pela Lei n. 5.540, de 28 de novembro de 1968, e a Lei n. 5.692, de 11 de agosto de 1971, que reorganizou o ensino de $1^{\circ}$ e $2^{o}$ graus - reforçaram o papel dos Conselhos de Educação, ampliando, especialmente, as funções do Conselho Federal de Educação (CFE), cujo desempenho foi decisivo na elaboração e no direcionamento da política educacional, a partir de então. De interesse para este texto, temos o registro de que a composição do CFE previa a representação de instituições privadas, de modo 
que o Conselho passou a ser alvo de poderosos lobbies privatistas, que favoreceram o crescimento hipertrofiado deste segmento da educação superior brasileira (VALE, 2011). Conforme Saviani (2010), a ousadia dos lobistas chegou ao ponto do envolvimento em corrupção, o que levou ao fechamento do Conselho Federal de Educação, em 1994, no governo Itamar Franco. Pela Medida Provisória n. 661, de 18 de outubro de 1994, foi instituído o Conselho Nacional de Educação em substituição ao CFE, cujos membros tiveram seus mandatos extintos. No ano seguinte, o funcionamento do Conselho Nacional de Educação (CNE) foi regulado pela Lei n. 9.131, de 24 de novembro de 1995, portanto, já no mandato de Paulo Renato Costa Souza como ministro da Educação do Governo de Fernando Henrique Cardoso. Nesse momento, todavia, a promiscuidade entre o público e o privado já vinha assumindo novas e variadas formas, que estão em curso até os dias atuais.

2. O campus Rebouças foi penhorado em um processo movido pelo município do Rio de Janeiro relativo à cobrança de IPTU. Foi nele que, em 5 de maio de 2003, uma aluna foi atingida por um tiro, resultando em processo ainda em trâmite.

3. O sistema de incentivos então prometido será duramente atacado pelo patronato nos anos seguintes. Na Convenção Coletiva de Trabalho da Educação Superior de 2008, por exemplo, o anuênio foi congelado e, no ano seguinte, substituído pelo triênio.

4. São elas: Sociedade de Ensino Superior do Pará Ltda. (Sespa), Sociedade de Ensino Superior do Ceará Ltda. (Sesce), Sociedade de Ensino Superior de Pernambuco Ltda. (Sespe) e Sociedade Tecnopolitana da Bahia Ltda. (STB).

5. O Prouni teve origem em 2004, pela Medida Provisória n. 213, de 10 de setembro de 2004, como uma resposta às demandas e pressões políticas do conjunto das IES privadas e das camadas sociais excluídas da educação superior. "Dessa forma, o desenho do programa foi delineado, tendo como ponto de partida a concessão de bolsas de estudos por parte dos estabelecimentos particulares aos estudantes pobres, associado à adoção de política afirmativa e à melhoria na qualificação de professores da rede pública da educação básica. Em contrapartida, as instituições participantes beneficiaram-se de nova renúncia fiscal" (CARVALHO, 2011, p. 1).

6. A Moena S.A. foi incorporada pela Estácio Participações S.A. em 31 de agosto de 2010 e extinta de pleno direito, sendo sucedida em direitos e obrigações pela Estácio Participações S.A.

7. São elas: Irep Sociedade de Ensino Superior, Faculdade Radial de Curitiba, Sociedade de Ensino Superior de Alagoas, Sociedade de Ensino Superior do Amapá, União Nacional de Educação e Cultura, Sociedade de Ensino Superior de Sergipe, Sociedade Interlagos de Educação e Cultura S/S Ltda., Sociedade Abaeté de Educação e Cultura Ltda., Faculdade Brasília de São Paulo Ltda., União Cultural e Educacional Magister Ltda., Sociedad de Enseñanza Superior S.A. e Maria Montessori de Educação e Cultura Ltda.

\section{Referências}

BRASIL. Conselho Federal de Educação. Parecer n. 422, de 4 de junho de 1970. Documenta, Brasília, DF, n. 115, p. 56-58, jun. 1970.

BRASIL. Conselho Federal de Educação. Parecer n. 1.205, de 28 de novembro de 1988. Documenta, Brasília, DF, n. 336, p. 163-188, dez. 1988.

CARVALHO, C.H.A. Reforma universitária e os mecanismos de incentivo à expansão do ensino superior privado no Brasil (1964-1984). 2002. 177f. Dissertação (Mestrado) - Curso de Ciências Econômicas, Instituto de Economia, Universidade Estadual de Campinas, Campinas. 
CARVALHO, C.H.A. Uma análise crítica do financiamento do Prouni: instrumento de estímulo à iniciativa privada e/ou democratização do acesso à educação superior? In: REUNIÃO ANUAL DA ANPEd, 34., 2011, Natal. Anais... Natal, 2011. Disponível em: <http://www.anped11.uerj.br>. Acesso em: 6 jul. 2012.

CAVALCANTI NETTO, J.U. Entrevista. In: HEYMANN, L.; ALBERTI, V. (Org.). Trajetórias da universidade privada no Brasil: depoimentos ao CPDOC-FGV. Brasília, DF: Capes; Rio de Janeiro: FGV/CPDOC, 2002. p. 327-351.

CHESNAIS, F. O capital portador de juros: acumulação, internacionalização, efeitos econômicos e políticos. In: CHESNAIS, F. (Org.). A finança mundializada: raízes sociais e políticas, configurações, consequências. São Paulo: Boitempo, 2005. p. 35-68.

DAVIES, N. O financiamento público às escolas privadas. Universidade \& Sociedade, Brasília, DF, v. 27, p. 74-91, 2002.

ESTÁCIO PARTICIPAÇÕES S.A. Demonstrações financeiras, em 31 de março de 2007a. Disponível em: <http://www.estacioparticipacoes.com>. Acesso em: 9 ago. 2011.

ESTÁCIO PARTICIPAÇÕES S.A. Informações anuais (IAN), data-base: 31 de março de 2007b. Reapresentação espontânea. Legislação societária. Disponível em: <http:// www.estacioparticipacoes.com/>. Acesso em: 9 ago. 2011.

ESTÁCIO PARTICIPAÇÕES S.A. Demonstrações financeiras padronizadas: empresa comercial, industrial e outras, data-base: 31 de dezembro de 2009. Legislação Societária. Disponível em: <http://www.estacioparticipacoes.com/>. Acesso em: 9 ago. 2011.

ESTÁCIO PARTICIPAÇÕES S.A. Visão. 2010. Disponível em: <http://www.estacioparticipacoes.com/estacio2010/web/conteudo_pt.asp?idioma=0\&conta=28\&tipo= 30093>. Acesso em: 22 fev. 2012.

ESTÁCIO PARTICIPAÇÕES S.A. Formulário de referência. 2011. Disponível em: $<$ http://www.estacioparticipacoes.com/>. Acesso em: 9 ago. 2011.

FERNANDES, F. Capitalismo dependente e classes sociais na América Latina. Rio de Janeiro: Zahar, 1973.

FERNANDES, F. A revolução burguesa no Brasil: ensaio de interpretação sociológica. 5. ed. São Paulo: Globo, 2006.

FONTES, V.; MENDONÇA, S.R. História do Brasil recente (1964-1992). 3. ed. São Paulo: Ática, 1994.

MARTINS, C.B.M.; VELLOSO, J. Balanço: as universidades privadas no contexto do ensino superior contemporâneo. In: HEYMANN, L.; ALBERTI, V. (Org.). Trajetórias 
da universidade privada no Brasil: depoimentos ao CPDOC-FGV. Brasília, DF: Capes; Rio de Janeiro: FGV/CPDOC, 2002. p. 797-827.

OLIVEIRA, F. A crítica à razão dualista: o ornitorrinco. São Paulo: Boitempo, 2006.

SAVIANI, D. Cumplicidade entre o público e o privado na história da política educacional brasileira. In: CONGRESSO LUSO-BRASILEIRO DE HISTÓRIA DA EDUCAÇÃO, 8., 2010. Anais... São Luís, 2010.

SGUISSARDI, V. Modelo de expansão da educação superior no Brasil: predomínio privado/mercantil e desafios para a regulação e a formação universitária. Educação \& Sociedade, Campinas, v. 29, n. 105, p. 991-1022, dez. 2008.

TIRADENTES, A. Educando trabalhadores na "universidade micro-ondas": novos modelos produtivos, trabalho docente e qualidade da formação humana sob o efeito do "mercado educador". In: MONKEN, M.; DANTAS, A.V. (Org.). Estudos de politecnia e saúde. Rio de Janeiro: EPSJV, 2009. v. 4, p. 95-119.

VALE, A.A. "As faculdades privadas não fazem pesquisa porque não querem jogar dinheiro fora": a trajetória da Estácio de Sá, da filantropia ao mercado financeiro. 2011. Tese (Doutorado) - Programa de Pós-graduação em Políticas Públicas e Formação Humana, Universidade do Estado do Rio de Janeiro, Rio de Janeiro.

Recebido em 25 de fevereiro de 2012.

Aprovado em 19 de junho de 2012. 